\title{
Measurements of Environmental Pollution in Industrial Area Using Magnetic Susceptibility Method
}

\author{
N. Kucer, I. Sabikoglu and N. Can \\ Faculty of Arts and Sciences, Department of Physics, Celal Bayar University, 45010 Manisa, Turkey \\ Gaziemir district of Izmir, the Aegean Free Zone, is an industry center of approximately 295 companies that \\ operate in lots of fields such as production, maintenance-repair, trade and that provide $1 / 3$ of total employment \\ in 21 free zones in Turkey. In this study, magnetic susceptibility values of soil samples taking from environment \\ of various factories in Aegean Free Zone have been determined. Magnetic susceptibilities of samples in low and \\ high frequency have been measured by Bartington MS2B magnetic susceptibility measurement device. All of \\ the samples have showed ferromagnetic characteristics and also their pseudosingle-domain structures and super \\ paramagnetic granule additives have been determined by evaluating their graphics connected to frequency.
}

PACS: 91.25.fd, 91.62.Rt

\section{Introduction}

The magnetic susceptibility of a material is a measure of its ability to become magnetized by an external magnetic field [1]. In the natural environment, the magnetisability tells us about the minerals that are found in soils, rocks, dusts and sediments, particularly Fe-bearing minerals. Greatness of magnetic susceptibility in soil is closely related with mineral and characteristics of elements which were found in soil. The measurements provide information similar to that produced by other mineralogical techniques like X-ray diffraction or heavy mineral analysis. The value obtained in magnetic susceptibility measurement of the soil would be roughly proportional to the mass of those minerals. Magnetic susceptibility measurement operates efficiently as chemical measurements on soil and sediment samples for monitoring anthropogenic pollutions. Two powerful applications of susceptibility measurements of soils are shown: the identification of polluted areas and the detailed mapping of these areas to reveal the extent of pollution [2-4].

In this paper, heavy metal pollution in topsoil samples which are taken from side various factories found in the Aegean Free Zone, Gaziemir-İzmir, Turkey has been determined by means of magnetic susceptibility method.

\section{Materials and methods}

\subsection{Sampling}

The Aegean Free Zone was opened in 1990 and was the first production-based modern of the other 21 Free Zones in Turkey. The Aegean Free Zone has been established in Gaziemir, İzmir-Turkey.

A total of 8 topsoil samples $($ depth $=0-10 \mathrm{~cm})$ were collected within the Aegean Free Zone. All the samples were collected with a plastic oar and kept in glass jars. The soil samples were air-dried at a few days, dried in oven for a day period and sieved through an $80 \mu \mathrm{m}$ sieve. The sieved soil samples were put in pots which are cleaned with pure water. Before this process, we recorded the values by measuring empty and full weight of pots.

\subsection{Magnetic susceptibility 2 (MS2) system calibration}

Bartington MS2 System has been calibrated electronically. In order to test the safety of measurements, system working has been tested with calibration samples. Values of system calibration are given in Table I.

Calibration of MS2B counting system.

TABLE I

\begin{tabular}{c|c|c|c}
\hline \hline Material & $\begin{array}{c}\text { Magnetic } \\
\text { behavior }\end{array}$ & Mass [g] & $\begin{array}{c}\text { Volume } \\
\text { susceptibility } \\
\text { (non-dimen- } \\
\text { sional) } \kappa\end{array}$ \\
\hline $\begin{array}{c}\text { pure water } \\
1 \% \begin{array}{c}\text { Fe-containing } \\
\text { sample }\end{array}\end{array}$ & diamagnetic & 10.00 & -0.9 \\
ferromagnetic & 12.00 & 150
\end{tabular}

\subsection{Measurement of samples}

Soil samples used in this study have been measured by Bartington MS2 and MS2B [5]. MS2 measurement system can be affected from electronic devices, vibration, metal things close to the measurement area and devices which can make magnetic field. These effects had been taken into consideration before starting the measurements. During the experiment, laboratory temperature has been kept at room temperature. Diamagnetic effect of sample pot was eliminated by the multiple computer programme. Graphics are plotted by using mass susceptibility $(\chi)$. Susceptibility measurements of all samples were recorded at low frequency. 


\section{Results and discussion}

The descriptions of the data distributions [magnetic susceptibility $\left(\chi_{\mathrm{LF}}\right.$ and $\left.\left.\chi_{\mathrm{HF}}\right)\right]$ in the topsoil samples are given in Table II. The median of specific magnetic susceptibility $\left(\chi_{\mathrm{LF}}\right)$ is $44 \times 10^{-8} \mathrm{~m}^{3} \mathrm{~kg}^{-1}$, ranging from $20.6 \times 10^{-8} \mathrm{~m}^{3} \mathrm{~kg}^{-1}$ to $115.5 \times 10^{-8} \mathrm{~m}^{3} \mathrm{~kg}^{-1}$. The $\chi_{\mathrm{LF}}$ values depend on geology of the area, sedimentation, and anthropogenic dope additives materials.

Susceptibility values of measured samples.

TABLE II

\begin{tabular}{|c|c|c|c|c|c|}
\hline \multirow{2}{*}{$\begin{array}{l}\text { Sample } \\
\text { number }\end{array}$} & Empty & Total & $\chi_{\mathrm{HF}}$ & $\chi_{\mathrm{LF}}$ & \multirow{2}{*}{$\begin{array}{l}\chi_{\mathrm{FD}} \\
{[\%]}\end{array}$} \\
\hline & \multicolumn{2}{|c|}{ weight $[\mathrm{g}]$} & \multicolumn{2}{|c|}{$\left[\times 10^{-8} \mathrm{~m}^{3} \mathrm{~kg}^{-1}\right]$} & \\
\hline 1 & 4.17 & 14.66 & 45.4 & 44.9 & 2.27 \\
\hline 2 & 4.17 & 15.93 & 20.2 & 21.6 & 4.76 \\
\hline 3 & 4.19 & 17.40 & 113.3 & 115.5 & 1.74 \\
\hline 4 & 4.13 & 16.70 & 84.9 & 89.1 & 5.62 \\
\hline 5 & 4.19 & 17.78 & 41.2 & 43.1 & 4.65 \\
\hline 6 & 4.14 & 15.82 & 33.0 & 38.2 & 13.16 \\
\hline 7 & 4.16 & 15.34 & 19.5 & 20.6 & 5.0 \\
\hline 8 & 4.17 & 17.14 & 48.1 & 50.9 & 4.0 \\
\hline
\end{tabular}

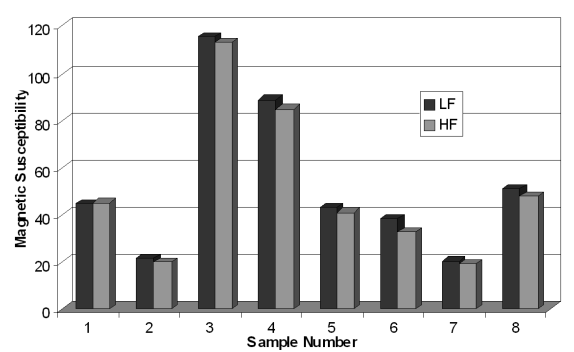

Fig. 1. Susceptibility values of samples both at low and high frequency.

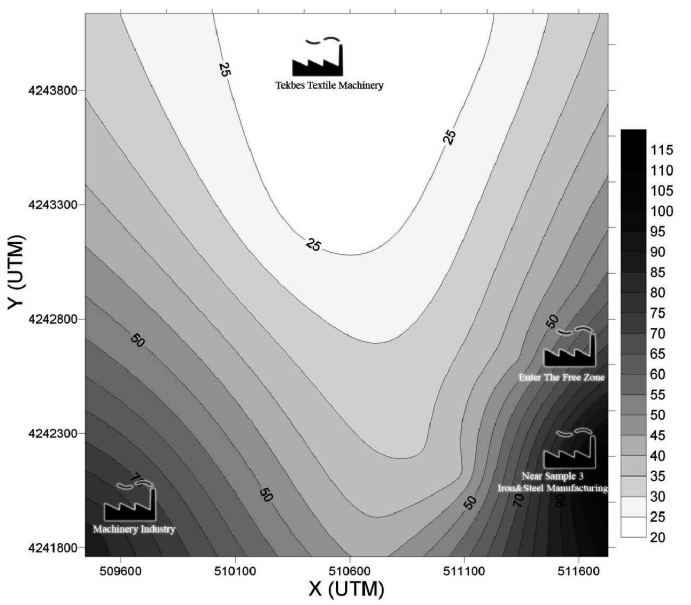

Fig. 2. Susceptibility values at low frequency.

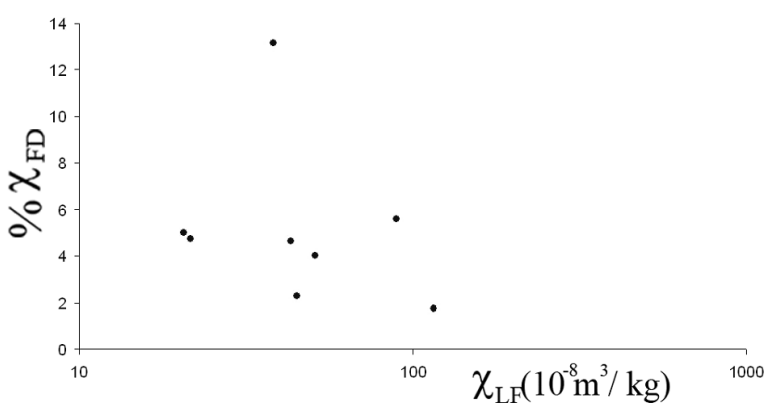

Fig. 3. A schematic $\chi_{\mathrm{LF}}-\chi_{\mathrm{FD}} \%$ scattering diagram showing typical positions of samples.

The susceptibility values of all samples were quite high. We may say that all of the samples have ferromagnetic characteristic and contain heavy metal ions. Also susceptibility values that connected low and high frequency were too close to each other (Fig. 1). The median of $\chi_{\mathrm{LF}}$ in the topsoil is lower compared to that of the other areas $[6,7]$.

Graphic plotted by susceptibility values according to the samples coordinates (UTM), taken from various areas in Aegean Free Zone, has been given in Fig. 2. The topsoil sample that was taken from Universal Spice Factory environment has highest magnetic susceptibility value. The topsoil sample that was taken from Tekbeş Textile Machine Factory environment has lowest magnetic susceptibility value. We suggest that entrance and exit of steel industry and processing factories vehicles increase the magnetic susceptibility.

The frequency-dependent susceptibility $\left(\chi_{\mathrm{FD}} \%\right)$ values are given in Table II. Dearing (1999) showed the relation between $\chi_{\mathrm{FD}} \%$ and the paramagnetic component. $\chi_{\mathrm{FD}} \%$ of our topsoil samples range from $1.74 \%$ to $13.16 \%$ with a mean value of $5.15 \%$. Dearing's $\chi_{\mathrm{FD}} \%$ model [1] predicted two types of magnetic clusters in our topsoil samples. A lot of samples with a $\chi_{\mathrm{FD}} \%$ values were placed between $2 \%$ and $6 \%$. These values correspond to a mixture of multidomain and stable single-domain. We suggest that there developed a soil of a mixture of supermagnetic and non-supermagnetic grains (Fig. 3). Only one value with $13.16 \%\left(\chi_{\mathrm{FD}} \%\right)$ was evaluated to be dominated by the frequency-dependent grains; hence the ferromagnetic grains are present in high concentration (Table II).

\section{Conclusions}

In summary, susceptibility values of the samples used in this study are high and thus we suggest that the soils may contain iron, nickel, lead, zinc etc. which are heavy ions. According to the size and type of soil granules, it can be considered that the soil is in a developed magnetic structure. For this reason, Free Zone has clearly a dirty structure as a heavy metal. From the studies related to the magnetic susceptibility, it has been seen that in the areas of industry facilities and the areas of combustion products of these facilities, susceptibility values 
are high [7]. It is also possible to determine heavy metals in the soils investigated using inductively coupled plasma optic emission spectrometer - ICP-OES.

\section{References}

[1] J.A. Dearing, in: Environmental Magnetism, Eds. J. Walden, F. Oldfield, J. Smith, Technical guide, No. 6, Quaternary Research Association, London 1999, p. 35.

[2] M. Hanesch, R. Scholger, Environmental Geology 42, 857 (2002).
[3] L. Schibler, T. Boyko, M. Ferdyn, B. Gajda, S. Höll, N. Jordanova, W. Rösler, Team MAGROX, Studia Geophys. Geodaet. 46, 43 (2002).

[4] K.M. Banat, F.M. Howari, A.A. Al-Hamad, Environ. Res. 97, 258 (2005).

[5] M. Ayvacıklı, M.Sc. Thesis, Celal Bayar University, Manisa, Turkey 2001.

[6] X.S. Wang, Y. Quin, Environmental Geology 49, 897 (2006).

[7] M. Canbay, A. Aydin, C. Kurtulus, J. Appl. Geophys. 70, 46 (2010). 